\title{
Software-Hardware Integration in Automotive Product Development
}




\title{
Other SAE books of interest:
}

Multiplexed Networks for Embedded Systems

By Dominique Paret

(Product Code: R-385)

\section{Automotive Software Engineering}

By Joerg Schaeuffele and Thomas Zurawka

(Product Code: R-361)

\section{Vehicle Multiplex Communication}

By Christopher A. Lupini

(Product Code: R-340)

\author{
For more information or to order a book, contact: \\ SAE International \\ 400 Commonwealth Drive \\ Warrendale, PA 15096-0001 USA \\ Phone: +1.877 .606 .7323 (U.S. and Canada only) \\ or +1.724 .776 .4970 (outside U.S. and Canada) \\ Fax: +1.724-.776.0790; \\ Email: CustomerService@sae.org; \\ Website: books.sae.org
}




\section{Software-Hardware Integration in Automotive Product Development}

Edited by John Blyler

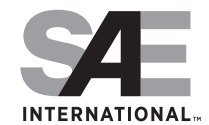




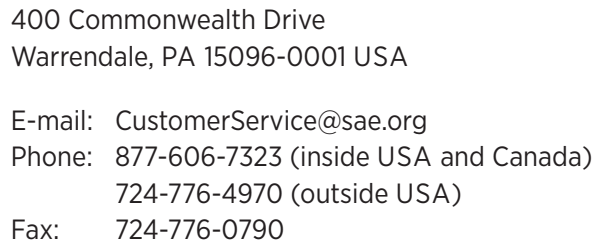

Copyright (c) 2014 SAE International. All rights reserved.

No part of this publication may be reproduced, stored in a retrieval system, distributed, or transmitted, in any form or by any means without the prior written permission of SAE International. For permission and licensing requests, contact SAE Permissions, 400 Commonwealth Drive, Warrendale, PA 15096-0001 USA; e-mail: copyright@sae.org; phone: 724-772-4028; fax: 724-772-9765.

ISBN 978-0-7680-8052-0

Library of Congress Catalog Number 2013949773

SAE Order Number PT-161

DOI 10.4271/ PT-161

Information contained in this work has been obtained by SAE International from sources believed to be reliable. However, neither SAE International nor its authors guarantee the accuracy or completeness of any information published herein and neither SAE International nor its authors shall be responsible for any errors, omissions, or damages arising out of use of this information. This work is published with the understanding that SAE International and its authors are supplying information, but are not attempting to render engineering or other professional services. If such services are required, the assistance of an appropriate professional should be sought.

\section{To purchase bulk quantities, please contact}

SAE Customer Service

e-mail: CustomerService@sae.org

phone: +1.877.606.7323 (inside USA and Canada)

+1.724 .776 .4970 (outside USA)

fax: +1.724 .776 .0790$

\section{Visit the SAE International Bookstore at books.sae.org}




\section{Table of Contents}

Introduction.

1

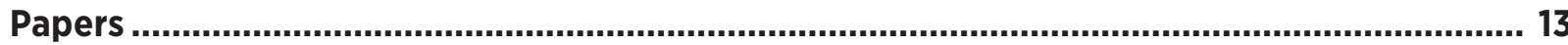

Adaptation of a "Virtual Prototype" for Systems and Verification

Engineering Development (2008-21-0043) Chandrashekar, M. S.,

Manjunath, B. C., Lumpkin, E. R., and Winters, F. J.

Verification and Validation According to IEC 61508: A Workflow to

Facilitate the Development of High-Integrity Applications (2009-01-2929)

Conrad, M., Friedman, J., and Sandmann, G.

Hardware/Software Design and Development Process (2006-01-0170)

Lumpkin, E., and Gabrick, M.

Using VHDL-AMS as a Unifying Technology for HW/SW Co-verification

of Embedded Mechatronic Systems (2004-01-0718) Egel, T. R., and Elias, N. J.

Virtual Prototypes as Part of the Design Flow of Highly Complex

ECUs (2005-01-1342) Krech, J., Mayer, A., and Raab, G.

To Test the Need and the Need to Test-Testing the Smart Controller

Network for the Chassis of Tomorrow (2008-21-0041) Deiss, H., Krimmel, H., and Maschmann, $\mathrm{O}$.

A Systems Engineering Approach to Verification of Distributed Body Control

Applications Development (2010-01-2328) Yang, J., Bauman, J., and Beydoun, A.

Highly Scalable and Cost Effective Hardware/Software Architecture for Car

Entertainment and/or Infotainment Systems (2004-21-0071)

Troemel Jr., H. A., and Burk, M.

Analysis of Interfaces and Interface Management of Automobile

Systems (2008-01-0279) Fritzsche, R.

Advancements in Hardware-in-the-Loop Technology in Support of

Complex Integration Testing of Embedded System Software (2011-01-0443)

Himmler, A., Waeltermann, P., and Khoee-Fard, M. 